\title{
Money, Social Status, and Capital Accumulation in a Cash-in-Advance Model
}

\begin{abstract}
This paper presents an infinite-horizon model of optimal capital accumulation with the social-status concern and the cash-in-advance constraint. When the cash-in-advance constraint applies to both consumption and investment, money is not superneutral. If only consumption is subject to the cash-in-advance constraint, inflation increases capital accumulation.
\end{abstract}

IN GROWTH AND ASSET-PRICING MODELS, wealth accumulation is often taken to be solely driven by one's desire to increase consumption rewards. The representative agent chooses his consumption path to maximize his discounted utility, which is defined only on consumption. Whereas this motive is important for wealth accumulation, it is, however, not the only motive. As social animals, people accumulate wealth also to gain prestige, social status, and power in the society. Possession of wealth is, to a considerable degree, a measure and standard of a person's success in a society. There is a recent literature that has paid attention to this motive ${ }^{1}$ which cogently argues that concern for social status is instrumental in obtaining nonmarket goods. For example, Cole, Mailath, and Postlewaite (1992) have presented a model in which people care about relative wealth because relative wealth affects mating. When matching is positively assortative on wealth, individuals who are higher in the wealth distribution for their sex will end up with richer mates and higher consumption. In particular, they have shown that if wealth determines the pattern of marriage, the reduced-form preferences of individuals will take the structure as follows:

$$
u\left(C_{t}, W_{t}\right)
$$

where $u(.,$.$) is the utility function, C$ is consumption, and $W$ is wealth. Another inter-

The authors thank Peter Howitt and anonymous referees of this journal for helpful comments.

1. See Frank (1985), Cole, Mailath, and Postlewaite (1992, 1995), Fershtman and Weiss (1993), Zou (1994, 1995, 1998), Bakshi and Chen (1996), and Fershtman, Murphy, and Weiss (1996), among others.

LIUTANG Gong is associate professor and HENG-Fu Zou is professor of economics, Peking University and Wuhan University. E-mail: ltgong@gsm.pku.edu.cn

Journal of Money, Credit, and Banking, Vol. 33, No. 2 (May 2001, Part 1)

Copyright 2001 by The Ohio State University 
pretation of this model is in line with the spirit of capitalism in the sense of Weber (1958, p. 53): "Man is dominated by the making of money, by acquisition as the ultimate purpose of his life. Economic acquisition is no longer subordinated to man as the means for the satisfaction of this material need. This reversal of what we should call the natural relationship . . . is evidently a leading principle of capitalism." ${ }^{2}$

With the wealth-is-status or the-spirit-of-capitalism model, many studies have tried to offer new perspectives on economic growth, savings, and asset pricing. In this paper, we extend the wealth-is-status model from a real economy to a monetary economy and examine how inflation and monetary growth affect capital accumulation. The relationship between inflation and growth has been a controversial topic in macroeconomics since the 1960s. In an early contribution, Tobin (1965) demonstrates a positive effect of inflation on capital accumulation as a result of portfolio shift from non-interest-bearing real balances to the capital stock. Since then, many plausible models based on explicit optimization over an infinite horizon have been produced. The famous infinite-horizon model belongs to Sidrauski (1967). He shows that if the agent maximizes an additive, discounted lifetime utility defined on consumption and real balances, and if the marginal product of capital depends only on the capital-labor ratio, then the steady-state value of capital accumulation is independent of monetary growth or inflation. This result is known as the superneutrality of money.

However, in a significant contribution to the literature, Stockman (1981) imposes the cash-in-advance constraint on both consumption and investment, and obtains the surprising result that a permanent increase in the rate of monetary growth leads to a decrease in the steady-state value of the capital stock. Yet if the cash-in-advance constraint applies only to consumption, then money is still superneutral in the long run. ${ }^{3}$ How does the inclusion of the wealth-is-status factor alter the conclusions in the Stockman model? This is our main task here.

The paper is organized as follows. Section 1 sets up an optimal growth model with both the social-status concern and the cash-in-advance constraint on consumption and investment. Section 2 analyzes the effects of monetary growth on the steadystate capital stock. It is shown that (1) with cash for consumption, inflation leads to more capital accumulation in the long run; and (2) with cash for both consumption and investment, inflation has an ambiguous effect on capital accumulation. Section 3 concludes.

\section{THE MODEL}

It is straightforward to extend the Stockman model to include the social-status concern. ${ }^{4}$ For simplicity, we assume that the representative agent's instantaneous

2. See Zou (1994, 1995, 1998), and Bakshi and Chen (1996) for details.

3. See Abel (1985) for further development on the short-run effects of inflation on capital accumulation with cash for consumption and cash for both consumption and investment.

4. Our notations follow Abel (1985) closely. 
utility is separable in consumption $C$ and wealth $W$. Furthermore, let $\gamma$ measure the agent's desire for social status. Then

$$
U_{1}(C)+\gamma U_{2}(W)
$$

Assumption 1: $U_{1}():. R^{+} \rightarrow R, U_{2}():. R^{+} \rightarrow R$ are twice continuously differentiable on $(0, \infty)$.

Assumption 2: $U_{1}^{\prime}>0, U_{2}^{\prime}>0, U_{1}^{\prime \prime}<0, U_{2}^{\prime \prime}<0$ on $(0, \infty)$ and

$$
\lim _{C \rightarrow 0} U_{1}^{\prime}(C)=+\infty, \lim _{W \rightarrow 0} U_{2}^{\prime}(W)=+\infty \text {. }
$$

The time preference discount factor of the agent is given by $\beta$, and $0<\beta<1$. The objective of the representative agent is to maximize the present discounted value of the utility of consumption and wealth:

$$
\sum_{t=0}^{\infty} \beta^{t}\left(U_{1}\left(C_{t}\right)+\gamma U_{2}\left(W_{t}\right)\right)
$$

and

$$
W_{t}=K_{t}+\frac{M_{t}+\tau_{t}}{P_{t}}
$$

where $W_{t}$ is total real wealth at time $t$, which is the sum of the capital stock, $K_{t}$, and real balances, $\frac{M_{t}+\tau_{t}}{P_{t}} ; \tau_{t}$ is the nominal money transfers received by the agent from the government at the beginning of time $t ; P_{t}$ is the money price of the homogeneous good at time $t ; \gamma U_{2}\left(W_{t}\right)$ is the utility the representative agent derives directly from wealth accumulated at time $t$.

The production function, $f\left(K_{t}\right)$, is neoclassical with

$$
f^{\prime}(.)>0 . f^{\prime \prime}(.)<0
$$

Now, the budget constraint for the agent can be written as

$$
C_{t}+K_{t+1}+\frac{M_{t+1}}{P_{t}}=f\left(K_{t}\right)+(1-\delta) K_{t}+\frac{M_{t}+\tau_{t}}{P_{t}}
$$

where $\delta$ is the rate of physical depreciation of capital.

As in Stockman (1981) and Abel (1985), the cash-in-advance constraint on consumption and investment is given in the general form 


$$
C_{t}+\mu K_{t+1}-\mu(1-\delta) K_{t} \leq \frac{M_{t}+\tau_{t}}{P_{t}}
$$

where $\mu=0$ or 1 . When $\mu=0$, equation (5) implies that the nominal value of consumption during period $t$ must be less than or equal to the money on hand at the beginning of the period $t$. When $\mu=1$, it says that the nominal value of consumption plus gross investment during a period cannot be greater than the money on hand at the beginning of the period.

Now, the representative agent chooses his consumption path, $\left\{C_{t}\right\}_{t=0}^{\infty}$, capital-accumulation path, $\left\{K_{t}\right\}_{t=0}^{\infty}$, and money-holdings path, $\left\{M_{t}\right\}_{t=0}^{\infty}$, to maximize his discounted utility

$$
\max _{\left\{C_{t}\right\}_{t=0}^{\infty},\left\{K_{t}\right\}_{t=0}^{\infty},\left\{M_{t}\right\}_{t=0}^{\infty}} \sum_{t=0}^{\infty} \beta^{t}\left(U_{1}\left(C_{t}\right)+\gamma U_{2}\left(W_{t}\right)\right)
$$

subject to the budget constraint (4) and the cash-in-advance constraint (5), with the given initial values of $K_{0}$ and $M_{0}$.

The Lagrangian function is defined by

$$
\begin{aligned}
L= & B^{t}\left\{U_{1}\left(C_{t}\right)+\gamma U_{2}\left(K_{t}+\frac{M_{t}+\tau_{t}}{P_{t}}\right)\right. \\
& +\lambda_{t}\left(f\left(K_{t}\right)+(1-\delta) K_{t}+\frac{M_{t}+\tau_{t}}{P_{t}}-C_{t}-K_{t+1}-\frac{M_{t+1}}{P_{t}}\right) \\
& \left.+v_{t}\left(\frac{M_{t}+\tau_{t}}{P_{t}}-C_{t}-\mu K_{t+1}+\mu(1-\delta) K_{t}\right)\right\},
\end{aligned}
$$

where $\lambda_{t}$ is the Lagrangian multiplier associated with the budget constraint (4), and it represents the marginal utility of wealth. $v_{t}$ is the Lagrangian multiplier associated with the cash-in-advance constraint (5). The first-order conditions for optimization are

$$
\begin{aligned}
& U_{1}^{\prime}\left(C_{t}\right)=\lambda_{t}+v_{t}, \\
& \beta \lambda_{t+1}\left(f^{\prime}\left(K_{t+1}\right)+(1-\delta)\right)+\beta \mu(1-\delta) v_{t+1} \\
& \quad+\beta \gamma U_{2}^{\prime}\left(K_{t+1}+\frac{M_{t+1}+\tau_{t+1}}{P_{t+1}}\right)=\lambda_{t}+\mu v_{t},
\end{aligned}
$$




$$
\frac{\beta \gamma}{P_{t+1}} U_{2}^{\prime}\left(K_{t+1}+\frac{M_{t+1}+\tau_{t+1}}{P_{t+1}}\right)+\frac{\beta}{P_{t+1}}\left(\lambda_{t+1}+v_{t+1}\right)=\frac{\lambda}{P_{t}}
$$

and the slackness condition:

$$
v_{t}\left(\frac{M_{t}+\tau_{t}}{P_{t}}-C_{t}-\mu\left(K_{t+1}-(1-\delta) K_{t}\right)\right)=0, v_{t} \geq 0
$$

Equation (8) is just the familiar condition, which asserts that the marginal utility of current consumption equals the marginal cost of current consumption, that is, the marginal utility of having an additional unit of wealth. Equation (9) implies that the marginal utility of having an additional unit of capital equals the marginal cost of having an additional unit of capital. Equation (10) states that the discounted value of the marginal utility of having an additional unit of wealth at the beginning of time $t+1$ equals the deflated marginal cost of having an additional unit of wealth in this period.

In the steady state, we have a constant capital stock, $K$, a constant level of consumption, $C$, and a constant (gross) rate of inflation, $\pi_{t}=\frac{P_{t}}{P_{t-1}}$, which is equal to the constant (gross) rate of monetary growth, $\sigma=\frac{M_{t}}{M_{t-1}}$. Furthermore, from the definition we know that both $\lambda_{t}$ and $v_{t}$ are constant. Then, in the steady state, we have ${ }^{5}$

$$
\begin{aligned}
C=f(K)-\delta K, & \\
\beta\left(f^{\prime}(K)+1-\delta\right)= & 1+\mu\left(\frac{\sigma}{\beta}-1\right)(1-\beta(1-\delta)) \\
& -\frac{\sigma \gamma U_{2}^{\prime}(K+C+\mu \delta K) A}{\beta\left(U_{2}^{\prime}(C)+\gamma U_{2}^{\prime}(K+C+\mu \delta K)\right)},
\end{aligned}
$$

where $A=\mu(1+\beta \delta)+(1-\mu) \beta$. We have also used the fact that $M_{t+1}=M_{t}+\tau_{t}$ in the budget constraint (4) in order to obtain the steady-state condition (12).

Equation (12) implies that the steady-state output is used for the agent's consumption and the replacement of depreciated capital stock. Equation (13) is the optimal rule of capital accumulation with the desire for social status. When $\mu=0$ and $\gamma=0$, it is reduced to

5. The formal proof of these steady-state conditions is available upon request. In addition, note that the necessary condition for the existence of a steady state is $\sigma \geq \beta+\beta \gamma \frac{U_{2}^{\prime}(K+f(K)-(1-\mu) \delta K)}{U_{1}^{\prime}(C)}$. 


$$
\beta\left(f^{\prime}(K)+1-\delta\right)=1,
$$

which is the discrete version of the modified golden rule, and it implies that money is superneutral when consumption is subject to the cash-in-advance constraint. But, with the concern for social status, namely, $\gamma>0$, even if the cash-in-advance constraint applies only to consumption, we still have

$$
\beta\left(f^{\prime}(K)+1-\delta\right)=1-\frac{\sigma \gamma U_{2}^{\prime}(K+C)}{\left(U_{1}^{\prime}(C)+\gamma U_{2}^{\prime}(K+C)\right)},
$$

Hence, capital accumulation is related to monetary growth, and money is not superneutral. We turn to a more detailed analysis of the effects of inflation in the next section.

\section{EFFECTS OF INFLATION}

Recall that Stockman (1981) has shown that (1) when the cash-in-advance constraint applies only to consumption, money is superneutral; and (2) if the cash-inadvance constraint applies to both consumption and investment, inflation always reduces capital accumulation in the long run. By including the wealth-induced social status in the model we can obtain a series of results that are very different.

\subsection{Cash for Consumption}

First let us consider the case where the cash-in-advance constraint applies only to consumption, that is, $\mu=0$ in (5). As shown in the appendix, we have

$$
\begin{aligned}
& \frac{d K}{d \sigma}=\frac{-\gamma U_{2}^{\prime}(.)}{\Delta(\mu=0) \beta\left(U_{1}^{\prime}(.)+\gamma U_{2}^{\prime}(.)\right)}, \\
& \frac{d C}{d \sigma}=\frac{-\gamma U_{2}^{\prime}(.)}{\Delta(\mu=0) \beta\left(U_{1}^{\prime}(.)+\gamma U_{2}^{\prime}(.)\right)}\left(f^{\prime}-\delta\right),
\end{aligned}
$$

where

$$
\begin{aligned}
\Delta(\mu=0)= & \frac{\sigma \gamma \beta\left(f^{\prime}-\delta\right)\left(U_{2}^{\prime \prime}(.) U_{1}^{\prime}(.)-U_{2}^{\prime}(.) U_{1}^{\prime \prime}(.)\right)}{\beta\left(U_{1}^{\prime}(.)+\gamma U_{2}^{\prime}(.)\right)^{2}} \\
& +\beta f^{\prime \prime}(K)+\frac{\sigma A U_{1}^{\prime}(.) \gamma U_{2}^{\prime \prime}(.)}{\beta\left(U_{1}^{\prime}(.)+\gamma U_{2}^{\prime}(.)\right)^{2}} .
\end{aligned}
$$


For saddle-point stability of the system, $\Delta(\mu=0)$ is negative. ${ }^{6}$ Therefore,

$$
\frac{d K}{d \sigma} \geq 0, \frac{d C}{d \sigma} \geq 0
$$

PROPOSITION 1: If the cash-in-advance constraint applies only to consumption, then, on the perfect-foresight path, inflation leads to more accumulation of capital and a higher level of consumption in the long run.

In fact, if the growth rate of the money supply increases, it will be more costly for the status-seeking agent to hold real balances than capital in order to maintain the same wealth level and the same social status. Hence, the agent will decrease his money holdings and invest more in the capital stock. This portfolio-shift process results in more capital accumulation and higher consumption in the long run.

\subsection{Cash for Both Consumption and Investment}

If both consumption and investment are subject to the cash-in-advance constraint, we have, from the appendix,

$$
\begin{aligned}
& \frac{d K}{d \sigma}=\frac{(1+\beta \delta) U_{1}^{\prime}-\beta\left(U_{1}^{\prime}(.)+\gamma U_{2}^{\prime}(.)\right)}{\Delta(\mu=1) \beta\left(U_{1}^{\prime}(.)+\gamma U_{2}^{\prime}(.)\right)}, \\
& \frac{d C}{d \sigma}=\frac{(1+\beta \delta) U_{1}^{\prime}-\beta\left(U_{1}^{\prime}(.)+\gamma U_{2}^{\prime}(.)\right)}{\Delta(\mu=1) \beta\left(U_{1}^{\prime}(.)+\gamma U_{2}^{\prime}(.)\right)}\left(f^{\prime}-\delta\right),
\end{aligned}
$$

where

$$
\begin{aligned}
\Delta(\mu=1)= & \frac{\sigma \gamma(1+\beta \delta)\left(f^{\prime}-\delta\right)\left(U_{2}^{\prime \prime}(.) U_{1}^{\prime}(.)-U_{2}^{\prime}(.) U_{1}^{\prime \prime}(.)\right)}{\beta\left(U_{1}^{\prime}(.)+\gamma U_{2}^{\prime}(.)\right)^{2}}+\beta f^{\prime \prime}(K) \\
& +\frac{\sigma(1+\beta \delta) U_{1}^{\prime}(.) \gamma U_{2}^{\prime \prime}(.)(1+\mu \delta)}{\beta\left(U_{1}^{\prime}(.)+\gamma U_{2}^{\prime}(.)\right)^{2}}
\end{aligned}
$$

and $\Delta(\mu=1)$ is still negative.

6. Unlike the stability analysis in Abel (1985), multiple equilibria may exist in our model. But, if $\frac{d \ln U_{2}^{\prime}(W)}{d \ln U_{1}^{\prime}(C)} \geq 1$, we know that one characteristic root is less than minus one, one root is between zero and one, and one is larger than one. The same condition will guarantee that $\Delta<0$. In this case, since only one of the three characteristic roots has modulus less than one, the system is saddle-point stable. The whole proof is rather lengthy, and it is available from the authors upon request. 
PROPOSITION 2: With cash required for both consumption and investment, the steady-state capital stock and consumption level will increase (decrease) with inflation when $\gamma U_{2}^{\prime}>(<)(1+\beta \delta-\beta) U_{1}^{\prime}$. If $\gamma U_{2}^{\prime}=(1+\beta \delta-\beta) U_{1}^{\prime}$, money is still superneutral.

Noticing that $\Delta(\mu=1)<0$, the proof of this proposition is immediate from equations (19), (20), and (21). The intuition for this proposition is as follows. When $\gamma U_{2}^{\prime}>(1+\beta \delta-\beta) U_{1}^{\prime}$, the agent has a stronger desire for the wealth-induced social status. With a higher rate of inflation, the cost of investment rises. But the agent will still shift more of his asset holdings from real balances to capital investment because the social-status effect of capital investment dominates the cost effect of inflation. Therefore, in the long run, inflation leads to more capital accumulation, which in turn brings in more output and more consumption. On the other hand, when $\gamma U_{2}^{\prime}<$ $(1+\beta \delta-\beta) U_{1}^{\prime}$, the agent is less concerned with the wealth-induced social status. Then the inflation cost of investment dominates the wealth effect of investment. In this case, inflation reduces long-run capital accumulation. Finally, when $\gamma U_{2}^{\prime}=$ $(1+\beta \delta-\beta) U_{1}^{\prime}$, these two effects cancel each other, and inflation does not affect investment and capital formation.

\subsection{Effects of the Desire for Social Status}

Please note that the desire for social status itself can lead to more capital accumulation and more consumption in the long run. As shown in the Appendix,

$$
\begin{aligned}
& \frac{d K}{d \gamma}=\frac{\sigma A U_{1}^{\prime} U_{2}^{\prime}}{\Delta(\mu) \beta\left(U_{1}^{\prime}(.)+\gamma U_{2}^{\prime}(.)\right)^{2}}, \\
& \frac{d C}{d \gamma}=\frac{\sigma A U_{1}^{\prime} U_{2}^{\prime}\left(f^{\prime}-\delta\right)}{\Delta(\mu) \beta\left(U_{1}^{\prime}(.)+\gamma U_{2}^{\prime}(.)\right)^{2}},
\end{aligned}
$$

where

$$
\begin{gathered}
\Delta(\mu)=\frac{\sigma \gamma A\left(f^{\prime}-\delta\right)\left(U_{2}^{\prime \prime}(.) U_{1}^{\prime}(.)-U_{2}^{\prime}(.) U_{1}^{\prime \prime}(.)\right)}{\beta\left(U_{1}^{\prime}(.)+\gamma U_{2}^{\prime}(.)\right)^{2}}+\beta f^{\prime \prime}(K) \\
+\frac{\sigma A U_{1}^{\prime}(.) \gamma U_{2}^{\prime \prime}(.) U_{1}^{\prime}(.)(1+\mu \delta)}{\beta\left(U_{1}^{\prime}(.)+\gamma U_{2}^{\prime}(.)\right)^{2}},
\end{gathered}
$$

and $\Delta(\mu)<0$. From equations (22) and (23), we know

$$
\frac{d K}{d \gamma}>0, \frac{d C}{d \gamma}>0
$$


PROPOSITION 3: Under the assumption of perfect foresight, the stronger the desire for wealth-induced social status, the higher the steady-state capital stock and consumption.

\section{CONCLUSIONS}

This paper has presented an infinite horizon model of optimal capital accumulation with the social-status concern and the cash-in-advance constraint. If only consumption is subject to the cash-in-advance constraint, inflation increases capital accumulation. If both consumption and investment are subject to the cash-inadvance constraint, the effect of inflation on capital accumulation is ambiguous. Specifically, when the agent has a stronger desire for the wealth-induced social status, he will shift more of his asset holdings from real balances to capital investment as a result of inflation because the social-status effect of capital investment dominates the cost effect of inflation. In this case, inflation leads to more capital accumulation. On the other hand, if the agent is less concerned with the wealth-induced social status, then inflation can reduce capital formation.

\section{APPENDIX}

Taking total differentiation in equations (12) and (13), we have

$$
\begin{gathered}
\left(\beta f^{\prime \prime}(K)+\frac{\sigma A U_{1}^{\prime}(.) \gamma_{2}^{f^{\prime}-\delta}(.)(1+\mu \delta)}{\beta\left(U_{1}^{\prime}(.)+\gamma U_{2}^{\prime}(.)\right)^{2}} \frac{\sigma \gamma A\left(U_{2}^{\prime \prime}(.) U_{1}^{\prime}(.)-U_{2}^{\prime}(.) U_{1}^{\prime \prime}(.)\right)}{\beta\left(U_{1}^{\prime}(.)+\gamma U_{2}^{\prime}(.)\right)^{2}}\right)\left(\frac{d K}{d C}\right) \\
=\left(\frac{\sigma A U_{1}^{\prime} U_{2}^{\prime}}{\beta\left(U_{1}^{\prime}(.)+\gamma U_{2}^{\prime}(.)\right)^{2}}\right) d \gamma+\left(\frac{A U^{\prime}}{\beta\left(U_{1}^{\prime}(.)+\gamma U_{2}^{\prime}(.)\right)}-1\right) d \sigma
\end{gathered}
$$

where $A=\mu(1+\beta \delta)+(1-\mu) \beta$.

Denote the determinant of the coefficient matrix as $\Delta(\mu)$. Then,

$$
\begin{aligned}
\Delta(\mu)= & \frac{\sigma \gamma A\left(f^{\prime}-\delta\right)\left(U_{2}^{\prime \prime}(.) U_{1}^{\prime}(.)-U_{2}^{\prime}(.) U_{1}^{\prime \prime}(.)\right)}{\beta\left(U_{1}^{\prime}(.)+\gamma U_{2}^{\prime}(.)\right)^{2}} \\
& +\beta f^{\prime \prime}(K) \frac{\sigma A U_{1}^{\prime}(.) \gamma U_{2}^{\prime \prime}(.) U_{1}^{\prime}(.)(1+\mu \delta)}{\beta\left(U_{1}^{\prime}(.)+\gamma U_{2}^{\prime}(.)\right)^{2}},
\end{aligned}
$$




$$
\begin{aligned}
& \frac{d K}{d \gamma}=-\frac{\sigma A U_{1}^{\prime} U_{2}^{\prime}}{\Delta(\mu) \beta\left(U_{1}^{\prime}(.)+\gamma U_{2}^{\prime}(.)\right)^{2}}, \\
& \frac{d C}{d \gamma}=-\frac{\sigma A U_{1}^{\prime} U_{2}^{\prime}\left(f^{\prime}-\delta\right)}{\Delta(\mu) \beta\left(U_{1}^{\prime}(.)+\gamma U_{2}^{\prime}(.)\right)^{2}}, \\
& \frac{d K}{d \sigma}=\frac{A U_{1}^{\prime}-\beta\left(U_{1}^{\prime}(.)+\gamma U_{2}^{\prime}(.)\right)}{\Delta(\mu) \beta\left(U_{1}^{\prime}(.)+\gamma U_{2}^{\prime}(.)\right)}, \\
& \frac{d C}{d \sigma}=\frac{A U_{1}^{\prime}-\beta\left(U_{1}^{\prime}(.)+\gamma U_{2}^{\prime}(.)\right)}{\Delta(\mu) \beta\left(U_{1}^{\prime}(.)+\gamma U_{2}^{\prime}(.)\right)}\left(f^{\prime}-\delta\right) .
\end{aligned}
$$

\section{LITERATURE CITED}

Abel, Andrew. "Dynamic Behavior of Capital Accumulation in a Cash-in-Advance Model." Journal of Monetary Economics 10 (1985), 55-71.

Bakshi, Gurdip, and Zhiwu Chen. "The Spirit of Capitalism and Stock-Market Prices." American Economic Review 86 (1996), 133-57.

$\rightarrow$ Cole, Harold, Gurdip Mailath, and Andrew Postlewaite. "Social Norms, Saving Behavior and Growth.” Journal of Political Economy 100 (1992), 1092-125.

. "Incorporating Concern for Relative Wealth into Economic Models." Quarterly Review, Federal Reserve Bank of Minneapolis, 19 (1995), 12-21.

$\rightarrow$ Fershtman, Chaim and Yoram Weiss. "Social Status, Culture, and Economic Performance." Economic Journal 103 (1993), 946-59.

Fershtman, Chaim, Kevin Murphy, and Yoram Weiss. "Social Status, Education, and Growth.” Journal of Political Economy 106 (1996), 108-32.

Frank, Robert. Choosing the Right Pond: Human Behavior and the Quest for Status. Oxford University Press, 1985.

Sidrauski, Miguel. "Rational Choice and Patterns of Growth in a Monetary Economy." American Economic Review, Papers and Proceedings, 57 (1967), 534-44.

$\rightarrow$ Stockman, Alan. "Anticipated Inflation and the Capital Stock in Cash-in-Advance Economy." Journal of Monetary Economics 8 (1981), 387-93.

$\rightarrow$ Tobin, James, "Money and Economic Growth." Econometrica 33 (1965): 671-810.

Weber, Max. The Protestant Ethic and the Spirit of Capitalism. New York: Charles Scribner's Sons, 1958.

Zou, Heng-fu. "The Spirit of Capitalism and Long-Run Growth." European Journal of Political Economy 10 (1994), 279-93.

"The Spirit of Capitalism and Savings Behavior." Journal of Economic Behavior and Organization 28 (1995), 131-43.

."The Spirit of Capitalism, Social Status, Money, and Accumulation.", Journal of Economics 68 (1998), 219-33. 